\title{
Memórias sobre a infância no meio rural: a escola e os outros espaços de sociabilidade (Minas Gerais - Brasil, 1920-1950)
}

\author{
Mônica Y. Jinzenji \& Ana M. Galvão \\ Universidade Federal de Minas Gerais, Brasil \\ Simone A. Silva \\ Professora $1^{\circ}$ e $2^{\circ}$ ciclo da rede municipal de Belo Horizonte, Brasil
}

\begin{abstract}
Resumo
Este trabalho analisa as representações sobre a infância por mulheres originárias de comunidades rurais do estado de Minas Gerais, na primeira metade do século XX, que migraram para Belo Horizonte quando adultas e que residem num bairro periférico da capital mineira. Utilizou-se entrevistas realizadas com 13 mulheres, dados demográficos e a legislação educacional do período. Nas entrevistas, a recorrente afirmação "eu não tive infância" pode ser compreendida pela contraposição feita por elas a uma suposta vivência infantil ideal, relacionada aos meios socialmente privilegiados, e à infância da atualidade, da qual elas se excluem. As memórias evocadas se referem à intensa rotina de trabalhos na roça e nas casas dos outros, à dificuldade em frequentar a escola, à precariedade das roupas, à ausência de brinquedos, mas também a momentos alegres de brincadeiras e à participação nas comemorações religiosas. Família, trabalho e religião concorrem com a escola como importantes espaços de sociabilidade.
\end{abstract}

Palavras-chave

Infância; Escola rural; Mulheres; Espaços de sociabilidade

\section{Introdução}

"Eu não tive infância" é a frase que marca o início da narrativa de grande parte das mulheres entrevistadas para a realização da pesquisa que 
deu origem a este texto, quando solicitadas a relatar sobre essa fase de suas vidas $^{1}$. A intensidade e a recorrência dessa frase foi um dos elementos motivadores deste trabalho, assim como a ausência da escola como lembrança espontânea no conjunto das memórias relacionadas aos primeiros anos de suas vidas. Somente quando provocadas a narrar sobre suas trajetórias escolares, algumas dessas mulheres passaram a relatar suas experiências na instituição escolar ou em práticas educativas relacionadas à aprendizagem da leitura e da escrita.

Discutiremos, neste trabalho, como um grupo de mulheres, em sua maioria negras, pertencentes aos meios populares, originárias do meio rural e atualmente residentes em um bairro de periferia de Belo Horizonte, capital de Minas Gerais, rememoram e ressignificam a infância e que lugar a escola ocupa nessas memórias. Foram entrevistadas, ao todo, 33 mulheres, das quais 13 ganharam destaque na presente análise, por terem vivenciado experiências escolares durante os primeiros anos de vida, numa época décadas de 1920 a 1950 - e locais em que as escolas eram escassas e muitos pais não viam com bons olhos a escolarização das filhas ou necessitavam dos seus serviços no orçamento doméstico, restringindo e, em alguns casos, proibindo a frequência à escola.

As mulheres cujas memórias analisamos neste artigo concederam uma ou mais entrevistas, que foram sempre realizadas no bairro onde a grande maioria delas reside atualmente, na região leste de Belo Horizonte. Todas elas nasceram e cresceram em diferentes localidades do interior do estado, residiam em fazendas próximas a arraiais ou em pequenas comunidades; algumas moravam nas redondezas de regiões urbanas ${ }^{2}$. Faziam parte de famílias que trabalhavam em terras de terceiros no sistema de "meia"3 ou arrendavam a terra4; muitas delas colaboravam com o trabalho da roça. Quando adultas, migraram para Belo Horizonte em busca de melhores condições de vida ou para realizar tratamentos de saúde, estabelecendo residência permanente na capital.

A história oral como metodologia para os estudos em história da educação possibilita abordar temáticas pouco acessíveis por meio de outras fontes, tais como a que propomos neste trabalho. Por meio do ato de rememorar, a partir do qual as mulheres reconstroem o passado, a própria escola é reconstruída, assim como as experiências vividas. Como discutem 
diversos trabalhos que problematizam essa metodologia, no próprio ato de narrar o sujeito reinventa-se, conferindo, muitas vezes, ao passado significações que somente podem ser compreendidas a partir do lugar - não apenas individual, mas também social - que ocupa no presente. Nesse sentido, memória individual e memória coletiva são consideradas indissociáveis 5 .

Analisamos os relatos orais relacionando-os a outras fontes documentais, tais como dados demográficos e enciclopédias toponímicas, que forneceram informações sobre as localidades de origem, além da legislação brasileira e mineira que trata da organização das escolas rurais no período estudado. Pelo fato de as experiências escolares terem sido rarefeitas, aparecem imprecisas e mescladas a outras experiências que muitas vezes suplantam a escola como espaço efetivo de aprendizagens e formação. Esses outros espaços são tão significativos nas memórias sobre a infância que é impossível desprezá-los.

Buscando compreender o significado de 'infância' para esse grupo de mulheres, utilizamos o conceito de representação, preconizado por Roger Chartier (1990), que nos auxilia na análise do conjunto de elementos atribuídos a uma suposta vivência infantil ideal, entendida como social e historicamente construída, representação da qual a maioria das entrevistadas se exclui. Ao mesmo tempo, esse conceito possibilita a compreensão dos referenciais próprios desse grupo de sujeitos para nomear e dar sentido às diferentes fases da vida e às suas experiências.

\section{Representações de infância e as etapas da vida}

As primeiras entrevistas realizadas nos conduziram a uma revisão de caráter metodológico, na medida em que à primeira pergunta - "Você poderia nos contar como foi a sua infância?" - seguia-se geralmente a resposta "Eu não tive infância" e, na sequência, relatos acerca da intensa rotina de trabalho na roça desde muito jovem. Aparentemente, a palavra 'infância' sugeria representações com as quais nossas entrevistadas não compartilhavam o sentimento de pertencimento. Após maior familiaridade com o vocabulário utilizado por elas, optamos pela modificação da pergunta para "Como era a sua época de menina?", que passou a gerar relatos mais diversificados que 
incluíam a participação em atividades religiosas e brincadeiras, além do trabalho, que continuou sendo a temática predominante.

Tal questão nos remete a reflexões acerca da historicidade da infância (Ariès, 1981) e à coexistência de vários tipos de representações e práticas "no seio de uma mesma sociedade, uma prevalecendo sobre a outra em determinado momento por motivos culturais e sociais que nem sempre é fácil distinguir" (Gélis, 1993, p. 328). Fazer um estudo da infância a partir do ponto de vista histórico significa, portanto, questionar as noções genéricas e abstratas que a tornam "absoluta", buscando compreender as infâncias de cada momento e lugar, considerando-se o lugar social, a etnia, as relações de gênero, enfim, a criança como sujeito social, cultural e histórico. Requer, portanto, como assinala Sarmento (1997, p. 23), distinguir a infância, como categoria social que assinala os elementos de homogeneidade desse grupo minoritário, das crianças, neste caso, as meninas, como referentes empíricos.

Além disso, a infância vivida e sentida pelas próprias crianças raramente deixa registros, fazendo com que a maioria das pesquisas em história da infância sejam feitas a partir da visão dos adultos a seu respeito, seja pelo estudo de documentos produzidos por esses adultos ou por sua memória em relação ao próprio passado. Desse modo, segundo Moysés Kuhlmann Jr. (1998, p. 31), "a história da criança é uma história sobre a criança". No caso desta pesquisa, buscamos compreender as representações das infâncias de um grupo social situado num contexto espacio-temporal específico, a partir dos relatos orais produzidos na idade adulta.

Muitas das mulheres por nós entrevistadas utilizam referenciais específicos para se referir e delimitar as etapas da vida, baseados em modos de significar o mundo, diferentes daqueles representados pela idade cronológica6 ${ }^{6}$ Isso pode ser verificado, por exemplo, na fala de Divina (75 anos) (grifos nossos) quando diz: "... fui criada na roça, só serviço; quando eu mudei meus dentes, eu já tava na roça trabalhando, com enxada..."7; ou no caso de Balbina (72 anos) (grifos nossos), que afirma: "eu era a menorzinha, eu subia no fogão 8 para ajudar ela a tirar aquela chaleira e fazia aquele café, um coador de todo tamanho". Em ambos os casos, as entrevistadas utilizam elementos do cotidiano, em que se entrelaçam o biológico e o cultural, que foram/são significativos para a produção da memória dos primeiros anos da vida. 
Outra referência muito recorrente nas entrevistas realizadas é a utilização da idéia de "ser menina" para significar a pouca idade: "Eu era menina, mas eu não esqueço disso. Então eu fui como uma escrava, sabe? Praticamente como uma escrava, só tinha o direito de trabalhar e mais nada, né?" (Graciliana, 59 anos). Na fala de Dulcina (69 anos), podemos ver como as representações das diferentes etapas da vida estão relacionadas a aspectos do presente que levam a uma contraposição entre o ser criança hoje e no passado, indicando a historicidade dos próprios conceitos: "antigamente não falava adolescente, né? Era menino ou já era adulto já [risos]! Agora também é rapaz na adolescência, né? Não tinha isso pra gente não (...) menina pequenininha, já era uma moça casada". A noção de adolescência e o seu status social são vistos com estranhamento e, na busca de um equivalente para ressignificar o passado, Dulcina utiliza os termos moça e rapaz. Da mesma forma, para significar a passagem da infância ao que, contemporaneamente, denominamos adolescência, muitas entrevistadas utilizam a expressão "quando eu era mocinha", às vezes situada cronologicamente: "quando eu fiquei moça, de 17 para 18 anos (...), boa pra casar (...)" (Divina, 75 anos). Isso demonstra não apenas a historicidade dos vocábulos que definem as diversas etapas da vida, mas também os atributos sociais relacionados ao uso e aos significados dessas denominações, reforçando a idéia de que "toda sociedade tem seus sistemas de classes de idade e a cada uma delas é associado um sistema de status e de papel" (Kuhlmann Jr. \& Fernandes, 2004, p. 28).

As relações intergeracionais, evocadas nas memórias das entrevistadas, cumpriam um lugar importante na delimitação das diferentes fases da vida. $\mathrm{O}$ esclarecimento das mudanças físicas da puberdade pelos/as adultos/as com quem conviviam, por exemplo, foi rememorado por algumas mulheres. Rosa (64 anos) se lembra do papel da professora no devido esclarecimento a respeito da menarca. Em sua memória, estava na escola quando foi surpreendida pela primeira menstruação; foi tomada, então, pelo pavor, pois acreditava que a morte estava próxima: "meu Deus, tô morrendo (...) meu Deus, por que a morte tá chegando depressa pra mim?". Ao ser questionada pela professora, que percebia seu incômodo, ela the respondeu que estava próxima da morte, "porque minhas tripa arrebentou tudo dentro de mim (...) porque tá saindo sangue de mim". Para Rosa, o contato com a escola 
supriu o que considera um misto de ignorância da mãe, mas também de consideração e respeito.

\section{Trabalho e escola}

O trabalho é o tema que predomina nas narrativas, seja ele relacionado às atividades rurais (ajudar no plantio, na colheita, no cuidado com os animais, no cozinhar e levar as refeições para os trabalhadores), seja ele doméstico (no cuidado com os irmãos mais novos, na arrumação da casa, buscando lenha ou trabalhando na casa de outros cuidando de crianças e como empregada doméstica). Todas elas trabalharam, como fizeram grande parte das crianças pobres do Brasil desde os séculos anteriores - situação que ainda permanece, na atualidade, em várias partes do País (Rizzini, 2000).

Em meados do século $X X$, a estrutura social do campo no Brasil se caracterizava pela coexistência de grandes propriedades - os latifúndios -, que se ocupavam da pecuária e da produção extensiva do café e da cana de açúcar, com médias e pequenas propriedades. Esses médios proprietários muitas vezes arrendavam parte das terras para famílias e para outros agricultores. Entretanto, a maioria (cerca de 85\%) da população rural era formada por pequenos proprietários, posseiros, assalariados temporários ou permanentes, que viviam em extrema pobreza (Mello \& Novais, 1998). Essa situação se aguçou a partir da década de 1960, quando se acentuou o processo de modernização da agricultura e a substituição da mão-de-obra assalariada por máquinas. Concomitantemente a isso, a industrialização e o desenvolvimento do comércio atraíam a migração para os centros urbanos, sendo essa a alternativa mais viável vista pelas famílias das participantes de nossa pesquisa, que começaram a chegar à capital do Estado a partir de meados de 1950, em busca de melhores condições de vida e de trabalho.

As famílias das mulheres investigadas na pesquisa eram originárias, em sua maioria, de pequenos povoados pertencentes a distritos situados na zona rural de municípios que possuíam, em média, 30.000 habitantes, nos quais a principal atividade econômica era a agricultura, que se realizava através do sistema de meia. De acordo com o censo de 1950, a população do estado de Minas Gerais era de 7.717.792 habitantes; mais da metade vivia na zona rural (4.457.880). Especificamente nas comunidades onde essas mulheres viviam, em média, $70 \%$ da população habitava a zona rural e os 
índices de alfabetização giravam em torno de $26 \%$. Eram localidades que, na maioria das vezes, não dispunham de escolas ou o acesso a essas instituições era muito difícil, por causa da distância e da precariedade dos caminhos; não dispunham de um sistema de atenção à saúde nem de equipamentos culturais como cinema, bibliotecas, livrarias, jornais. As atividades industriais eram rudimentares, restringindo-se às indústrias de transformação e beneficiamento de produtos agrícolas (IBGE, 1950). Assim, as famílias que viviam nessas áreas tinham como principal ou única alternativa dedicar-se aos trabalhos de plantio e colheita (do milho, feijão, café, algodão, mandioca) e à criação de pequenos animais, trabalho que envolvia toda a família. Nessas condições, "uma criança de cinco anos já é de muita serventia no trabalho", sendo importante utilizar seus serviços, pois, quando crescem, não se dispõem tanto a ajudar, diz um depoente da pesquisa de Rodrigues (1993) ao se lembrar das condições de vida no norte do estado de Minas Gerais, na primeira metade do século XX.

Entretanto, é importante salientar que o lugar do trabalho na vida das meninas e na organização familiar sofria nuances de acordo com a história de cada uma delas: algumas ajudavam na produção de alimentos para a subsistência familiar, outras recebiam algum dinheiro para auxílio no sustento da família, havendo as que utilizavam o dinheiro para pequenos gastos pessoais, como aponta Gannan (1995) em suas pesquisas. Para a maioria das depoentes de nosso estudo, a intensa rotina de trabalho é lembrada como sofrimento, mas, em alguns casos, a ajuda nas atividades da roça visava receber algum dinheiro para que pudessem comprar um sapato ou uma roupa melhor. Desse modo, nem todas as meninas trabalhavam para ajudar no orçamento familiar: nas memórias de algumas, transparece mais a satisfação de ter dinheiro próprio para gastar com o que quisessem do que o gosto pelo trabalho, à semelhança do que discute Rizzini (2000, p. 390) ao analisar depoimentos de crianças entre 7 e 14 anos, trabalhadoras dos canaviais de Pernambuco, no sisal e nas pedreiras da Bahia e na periferia de São Paulo. Temos como exemplo o caso de Graciliana (59 anos):

Então, aí a gente ia, comprava... eu lembro, na colheita de café, o primeiro sapato que eu calcei era de plástico e era azul ainda, sabe? Azulzinho assim. Foi comprado com dinheiro de colheita de café. Assim, a gente era menino ainda, sabe? E aquilo era uma alegria olhar praquele negócio azul no pé rachado! 
De modo semelhante, situa-se o depoimento de Dulcina (69 anos), que afirma: "Eu apanhava muito café, né? Pra ganhar um trocado pra comprar uma roupinha pra gente... Chegava a festa da padroeira, que é Santana, aí eu queria vestir um vestido, né, melhor, aí eu tinha que apanhar café pra comprar pra mim". Além disso, a depender da condição da família, as mulheres não se envolviam com o trabalho da roça, ficando na companhia da mãe, cuidando da casa, dos irmãos e dos animais. Como afirmam Dourado, Dabat, e Araújo (2000, p. 420), analisando relatos de velhos canavieiros de Pernambuco, o chefe de família, na maioria dos casos o pai, é que assumia a responsabilidade diante do proprietário das terras. As mulheres se envolviam com o trabalho da lavoura nos casos de doença ou morte do chefe de família 9 . É o caso de Benedita (64 anos), que nunca precisou trabalhar na roça; ajudava nos afazeres de casa, cuidando dos irmãos mais novos ou levando comida para os trabalhadores. Sua família foge do perfil da maioria das famílias aqui analisadas; seu pai arrendava terras para iniciar o cultivo: "Ele arrendou, era tipo aluguel, né? Você mudava pra lá (...), ele tinha o compromisso de formar uma lavoura, que tava pequenininha. Então ele tinha que deixar, durante cinco anos, ele tinha que deixar aquela lavoura formada com todos os pés de café já produzindo". Sua mãe trabalhava em casa como costureira.

Mas, em todos os casos, o trabalho recebia, nas memórias, uma carga de negatividade, especialmente ao ser colocado como empecilho para continuar os estudos. Para a maioria das mulheres entrevistadas, a possibilidade de estudar representava um dos aspectos mais significativos da infância; entretanto, era impossivel conciliar os estudos com o trabalho, principalmente no caso das famílias numerosas, que é a característica das participantes da pesquisa. Em média, pertenciam a famílias que possuíam entre 6 e 12 filhos, o que tornava inviável que as crianças, ou a maioria delas, frequentassem a escola. É o que podemos observar nos relatos de Dolores (69 anos), quando afirma que apenas seus irmãos mais velhos estudaram: "O mais velho estudou, o mais velho, né? (...), a minha irmã mais velha estudou... Foi só nós que não estudou. Mais, mais pra cá, né? A mais velha tem um pouco de estudo, na fazenda dava estudo". Os filhos mais novos não puderam estudar em virtude do falecimento do pai; a ausência do principal provedor determinava a reorganização da dinâmica familiar, impossibilitando a 
frequência à escola, pois todos os membros da família passavam a ser imprescindíveis no sustento, tendo que ajudar no trabalho da roça.

Conciliar escola e trabalho é sempre mencionado como uma das tarefas mais difíceis, pois se trabalhava em um dos períodos do dia e, no outro, estudava-se, muitas vezes tendo que percorrer longas distâncias a pé, o que contribuía para o abandono dos estudos, como podemos observar nos depoimentos abaixo:

A gente ia pra roça pra poder trabalhar, às vezes de manhã cedinho, minha filha, era assim: se a gente estudasse na parte da manhã, de manhã a gente ia pra aula e quando chegasse tinha que ir pra roça. Se estudasse na parte da tarde, tinha que ir de manhã pra roça e vinha pra poder ir pra aula (Beatriz, 56 anos).

Os trabalhos domésticos, sejam eles realizados na própria casa ou nas casas dos outros, também competiam com os estudos. Algumas meninas saíram da casa dos pais bem novas, para trabalhar e morar na casa de outra família, onde cuidariam das crianças e fariam os serviços domésticos. Muitas vezes não eram pagas por esse trabalho, recebendo, como troca, moradia e alimento. Nesses casos, apesar de morarem em localidades mais urbanizadas, também eram privadas da oportunidade de estudar, além de não conviverem com sua família.

Mas eu pouco aprendi. Depois, com essa família mesmo que eu fui pra cidade, não estudei também. Todo mundo saía pra estudar e eu ficava vigiando a menina e a casa, sabe? E assim, às vezes escola, aqui em Abre Campo mesmo, a escola era a metade de um quarteirão, todo mundo saía pra escola e eu ficava dentro de casa com a menina, não podia ir, sabe? E eu não estudei. Quando eu fui aprender a ler um pouco, já foi aqui, eu já tava velha. A cabeça já não funcionou mais assim, sabe? (Graciliana, 59 anos).

O convívio com outra realidade, com crianças mais abastadas, e a comparação com o tempo atual alimentam a postura crítica em relação ao passado, reforçando a afirmação de que não tiveram infância: "Esse negócio agora de tirar os menino pequeno pra trabalhar, quando a gente era pequena já começava a trabalhar, né? Agora não pode trabalhar mais!" (Dulcina, 69 anos).

\section{Brinquedos e brincadeiras}

Apesar da intensa rotina de trabalho, as mulheres entrevistadas também tinham, às vezes, tempo para as brincadeiras. Algumas delas relatam 
que, enquanto a mãe ou as irmãs mais velhas trabalhavam lavando roupa no rio, elas ficavam às voltas subindo e se balançando em árvores, comendo frutas, nadando no rio e se pendurando nas porteiras. Mas a maioria delas brincava geralmente à noite, depois de encerrado o serviço, em noites de lua clara. Entre as brincadeiras presentes nessas memórias estão as brincadeiras de roda, passar anel, chicotinho queimado, esconde-esconde, pega-pega ${ }^{10}$, casinha, fazer comidinha. As noites também possibilitavam a interação com os adultos que, à beira do fogão, contavam histórias: "Tinha os contador de história (...) às vezes a gente ficava assim (...) na beirada do fogão esquentando fogo, na época era fogão de lenha, aí mamãe contava muita história pra nós" (Beatriz, 56 anos).

Em relação aos brinquedos, Graciliana (59 anos) traz a recordação que marca a memória de várias outras mulheres, a de que nunca teve uma boneca, mais um motivo pelo qual afirma não ter tido infância: "Mas assim, nunca tive boneca, nunca tive... tudo que hoje as criança têm eu nunca tive na minha infância. Só tive uma enxada na minha mão pra trabalhar". Não ter tido uma boneca e nem ter tido calçados ou roupas é recuperado na memória em função da contraposição, tanto com o trabalho na roça, quanto com a infância dos netos na atualidade, em que a carência de brinquedos e de vestuário não se fazem tão presentes; hoje, para elas, as crianças escolhem o que querem ganhar, enquanto Rosa (64 anos) diz ter ganhado o primeiro presente de Natal aos oito anos de idade:

Não, eu não tinha nove ainda não, era uns oito anos, eu vim pra Itabira passar Natal na casa duma prima da mamãe, muito pobrezinha, então na noite de Natal, ela falou assim "aqui ó, Rosa, um presente de Natal pra você". Quando eu abri era uma fita lilás de cetim. Aquilo foi o presente, a coisa melhor... Parecia que eu tava ganhando o mundo com aquilo. Primeiro presente de Natal, com oito anos: uma fita lilás, grande assim, lilás.

No cotidiano dessas meninas, elas próprias, com a ajuda de adultos, fabricavam os brinquedos com os elementos que tinham ao redor, que caracteriza o que João Amado (2007) define como "brinquedos populares". Temos, como exemplo, as bonecas de milho e de pano, as representações de animais, a culinária infantil, as miniaturas de utensílios domésticos ${ }^{11}$ e os adornos com flores utilizados nas coroações. Dulcina (69 anos) brincava de boneca de sabugo de milho e cavalinho de banana: 
Pegava um paninho, ia enrolando no sabugo, botava esse paninho em cima da cabecinha do sabugo, amarrava aquela tira de pano assim, fazia os braços do sabugo. E os balainho de coisa, tinha os balainho pequeninho, a gente trazia as boneca nos balainho e ali que era as camas das boneca. Brincava com aquilo. $E$ banana verde; a gente pegava as banana verde, enfiava aqueles pauzinho de bambu nas banana e fazia aquele tanto de cavalinho nas banana verde. Aí brincava com as menina de comadre, aquele negócio de batizar menino, a gente brincava desse jeito! Mas boneca mesmo eu nunca possuí; nunca tive uma boneca.

Balbina (72 anos) vestia o sabugo de milho com as folhas de mutamba ${ }^{12}$, uma árvore de folhas macias: "E a infância nossa era essa. $E$ foi quando que eu fui crescendo mais, ficando maiorzinha, tudo, aí a minha irmã mais velha fez as boneca de tecido, né?". A ajuda dos adultos, geralmente de uma irmã mais velha ou da mãe, é também recorrente nas memórias, como no caso de Benedita (64 anos), cuja mãe encomendou na olaria uma trempe e panelinhas de barro, com as quais ela brincava de fazer comidinha. Rosa (64 anos) também se lembra de brincar de casinha; a mãe fazia um "fogãozinho à lenha" nos fundos da casa, comprava panelinhas de ferro e dava um pouco de arroz, feijão cozido, carne. Junto com colegas, fazia batizado de boneca,

que era batizado mesmo. Aí já entrava as mãe, já fazia aquelas, colocava uma mesa no... no terreiro, e ia, aos batizado de cada boneca tinha aquela festa; e era almoço mesmo, como se fosse batizado de gente grande. Fazia arroz, tutu, macarrão, frango, ali batizava boneca, arrumava o padre, de mentirinha, né, tinha as comadre, a gente fazia aquele batizado e ficava ali todo mundo entrava na festa e comia.

Essas brincadeiras estavam relacionadas ao universo "adulto" feminino, em que as meninas não só reproduziam as funções que as mães, as irmãs mais velhas e elas próprias realizavam na rotina doméstica, mas também ressignificavam a própria cultura, num movimento ativo e criativo, conforme nos lembram Amado (2007) e Gouvêa (2002). Nessas brincadeiras, a temática religiosa é bastante marcante, a ponto de os batizados das bonecas serem considerados "verdadeiros", ou, nas palavras de Rosa (64 anos), "era batizado mesmo", envolvendo a participação das mães. Além de batizar as bonecas, Rosa também representava a coroação no quintal de casa, utilizando uma enorme pedra como altar:

uma fazia de Nossa Senhora e ficava com a mão posta e as outras coroava. Colocava a coroa, aí fazia uma coroa de laranjeira, flor de laranjeira, minha mãe 
arrumava um cipó, e aquele cipó era trançado, e colocava um tanto de flor de laranjeira, e aí era a coroa que a gente arrumava pra coroar a virgem Maria. (...) muito... assim, saudável, né, que igual tipo de hoje é computação, é... coisa, tudo, e a gente não tinha maldade naquela época.

Mais uma vez, a comparação com o presente se apresenta como contraponto, dessa vez valorando as brincadeiras de sua época de menina como saudáveis, ao contrário dos jogos eletrônicos dos dias de hoje. Podemos perceber que, para as mulheres entrevistadas, a possibilidade de brincar é um forte elemento constitutivo da infância e, quanto mais se lembravam dos detalhes desses momentos, mais tendiam a considerar sua época de menina como época feliz, de diversão e sem "maldades".

\section{Festas religiosas}

Era lindo! Era muito bonito! E ia aquela porção de menina tudo vestida de virgem também, a que já tinha coroado primeiro, pra subir no altar, ficava até embaixo cheio. A que ia coroar ficava atrás da santa, e uma que ia oferecer palma de um lado, a outra, a outra também ia oferecer palma do outro lado, e as outra, tudo que já tinha coroado, ou ia coroar, mas tudo vestida de virgem. Todas vestida, era cor de rosa, azul claro, e branco (Maria, 91 anos).

É com esse entusiasmo e alegria que as nossas entrevistadas falam sobre as festas e comemorações religiosas que aconteciam em suas comunidades, na época "de menina": as novenas, as coroações do mês de maio, as festas dos santos e padroeiros. Esses ritos católicos ${ }^{13}$ significavam muito mais do que momentos dedicados à religiosidade; eram também momentos de socialização, de estar com os amigos, de brincar, de arrumar namorado, de interação com a comunidade mais ampla. Como nos afirma Sanchis, "(...) a romaria é vivida como festa, quer dizer, como acontecimento total, que se constitui em ruptura do quotidiano, irrupção de um 'outro' universo" (1983, cit. por Souza, 2009, p. 2). É o que percebemos quando, nas entrevistas, muitas memórias traduzem esses festejos como momentos nos quais as diferenças sociais e econômicas eram diluídas, a rotina de trabalhos pesados na roça era esquecida e todos tinham a oportunidade de participar. Auxiliadora (81 anos) afirma que, mesmo sendo pobre, foi sorteada para organizar a festa de Nossa Senhora, ilustrando o que Alba Zaluar discute sobre as festas religiosas como um "tempo de exceção" (1983, p. 72) . 
Era mês de maio. Era o Rosário e Santa Efigênia. E o mais festa de Nossa Senhora do Rosário, quando tinha mês de maio, né? A gente era sorteado, não era só a pessoa ser rico pra ser sorteado não. Eu mesma já fui sorteada, eu já fiz a festa de maio. (...) Era muito divertido, tinha aquela procissão, saía todo mundo com vela, todo mundo muito ajeitado... Tinha aqueles leilões, dava muita coisa pra igreja...

É importante demarcar que a participação nas festas religiosas era uma das oportunidades em que meninas e moças podiam ter papel ativo e até mesmo lugar de centralidade nos eventos socialmente valorizados, sendo possivelmente esse o motivo pelo qual esses eventos são imbuídos da idéia de algo "sublime". Em muitos casos, a religiosidade em si não é trazida como foco, mas sim os desdobramentos que os diversos rituais possibilitavam: de usar um vestido novo branquinho, de poder sair de casa à noite, lanchar nas casas dos outros, encontrar e brincar com colegas, aprontar confusões, arrumar namorado. Conforme Montes (1998, p. 159), no Brasil, as festas religiosas representam o momento de ruptura e transição entre a intimidade da vida doméstica e o espaço público, em que se produzem ressignificações dos motivos e significados das celebrações. Além disso, "conferem aos que delas participam uma nova forma de projeção social - ainda que este seja apenas o espaço restrito da rua, do grupo de vizinhança ou do bairro em que os celebrantes dessas alegres devoções são conhecidos" (Montes, 1998, p.160). Alguns exemplos são ilustrativos:

Nossa Senhora, alembro, minha fia, era linda, linda! Linda, linda, linda... Muita companhia, enchia a rua assim, de mulher, ia descendo aquela fila de mulher, tudo junto que a gente fazia pra ir pra festa, uai. Pra arrumar namorado na praça, né? (...) namorar bonitinho! (...) Minha mãe não gostava não, ela era braba, nossa, era igual uma onça (Dolores, 69 anos).

Tinha as moças que ensaiava as crianças pra cantar as músicas das rezas, e tinha as pessoas que era nomeadas, por exemplo, alguém ali que era da fazenda, por exemplo, que organizava, então tinha, por exemplo, me nomeavam como se eu fosse, eu ia ser a festeira. Então eu ia ser a festeira, eu ia ser responsável por arrumar as meninas pra coroar, ir nas casa pedir os pai pra deixar as meninas coroar, as meninas que fosse coroar, os pais tinha que comprar as roupas adequadas, o vestuário de acordo, e contribuir com um [palavra inaudível], era uma doação em dinheiro. E ou então doava alguma coisa, frango, leitão, uma saca de milho, feijão, alguma coisa, era alguma coisa que pudesse reverter em dinheiro, né? (Benedita, 64 anos).

Além dos ritos católicos, outras manifestações culturais e religiosas também fizeram parte dessas memórias sobre a infância, como o congado, a 
folia de reis, os marujeiros, as festas juninas e ritos pagãos, como os rituais para acabar com a seca, por exemplo. Tal diversidade retrata a rica e complexa formação da população mineira, que se desdobrou sob influências européias, africanas e indígenas.

\section{Escolas rurais em Minas Gerais: vestígios}

No Brasil, a denominação "escola rural" será criada no final do século XIX, ganhando destaque nos discursos oficiais desse período pela suposta precariedade material e humana (Musial, 2011). Na década de 1920 destacam-se as iniciativas governamentais para o desenvolvimento das escolas rurais a partir do movimento denominado "Ruralismo Pedagógico", que buscava conter o fluxo migratório para os grandes centros, desenvolvendo estratégias educacionais que valorizassem a cultura do campo, incentivando, assim, a permanência e a fixação das populações rurais. Essas políticas foram sendo desenvolvidas nas décadas seguintes, sendo marcadas pela descontinuidade e alternância de responsabilidades entre a União, os Estados e Municípios, o que acarretava a supressão de escolas, a ausência de fiscalização e o prejuízo no desenvolvimento e consolidação desses estabelecimentos (Coelho, 2009; Malheiros, 2009; Pinho, 2009).

A precariedade na atenção às demandas da população residente em localidades afastadas dos centros urbanos fazia com que a iniciativa particular fosse uma das alternativas encontradas por muitas famílias, entre as quais as de três mulheres participantes da nossa pesquisa. As memórias sobre as experiências escolares ou a aprendizagem da leitura e da escrita na infância são geralmente traduzidas como tendo sido efêmeras, seguidas do abandono em consequência da incompatibilidade com o trabalho. Na fala de Graciliana (59 anos),

Estudei pouco, porque lá, inclusive, nessa fazenda lá tinha uma escola, tipo vocês vê hoje mostrando aí na televisão, escola rural, sabe? Vinha menino de longe estudar, mas nós mesmo estudamo pouco, porque não podia, tinha que trabalhar (...). Eu lembro assim, quando a gente podia ir, ia à noite, né? $\mathrm{E}$ a luz era lampião, sabe? Mas durante o dia tinha a escola, tinha criança que vinha de longe, sabe? (...) Mas eu pouco aprendi.

O fato de morarem em localidades afastadas que não dispunham de escolas e a necessidade de caminhar longas distâncias era outra dificuldade 
que, agregada ao intenso ritmo de trabalho, fazia com que muitas das meninas abandonassem a escola. Segundo Margarida (70 anos): "tinha escola longe. Era quase mais de légua pra andar pra ir pra escola, mas nós ia todo dia de manhã. Eu freqüentei só uns três meses e ela me tirou, por conta do serviço na fazenda, né? (...) e disse que eu não podia estudar mais não, porque eu tinha que trabalhar".

Para algumas famílias, a experiência de migração era motivada não apenas pela ausência de terras para cultivar, mas também pela impossibilidade de dar continuidade aos estudos. Assim foi o caso de Benedita, uma das mais novas de sete irmãos: "Não, depois dessa fazenda, lá só fazia até o terceiro ano primário ${ }^{15}$, eu... E aí só nessa cidade que tinha... E aí já era... meia légua".

Eu parei, né? E só meu irmão fez o quarto ano primário lá, depois ele veio pra Teixeira, porque a minha irmã, a Isabel, já tinha casado (...) e mudou pra Teixeira, que é uma cidade mais pro lado de São Cristóvão, né, mais próximo. Então meu irmão veio pra cá, porque lá já tinha ginásio, né, que falavam. Tinha ginásio e ele veio estudar mais. E depois o meu irmão abaixo de mim também veio estudar cá em Teixeira (Benedita, 64 anos).

Ser menina era outro fator que, se não impedia o estudo, limitava a permanência na escola, visto que muitas famílias traziam a concepção de que o domínio da escrita pelas filhas poderia levá-las a escrever cartas para rapazes. Desse modo, muitas só aprenderam a assinar o próprio nome, como afirma Margarida (70 anos): "só aprendi a assinar meu nome. Quando eu comecei a ler alguma coisa, ela me tirou: 'não, você não pode ler não, porque você é muito pra frente, senão você vai escrever carta à revelia pros outro', e me tirou". Na família de Divina (75 anos), os irmãos tiveram o privilégio de estudar com o professor particular contratado pelo seu pai. Além dos irmãos, seus primos, primas e outros meninos de outras fazendas também iam estudar, enquanto ela tinha que "ir pra roça arrancar batata e mandioca, pra cozinhar pra dar aos outros que tava estudando pra comer. E fazer café com leite... o dia que tinha requeijão, era cortado o requeijão e pôr tudo na mesa pros aluno...". Segundo seu pai: "'ô, fia, cê num vai estudar não. Porque moça não precisa estudar'. Antigamente era assim. Porque às vezes estudava, aí ia escrever carta pra rapaz". Auxiliadora (81 anos) afirma ter estudado até o terceiro ano e teve que parar após a morte da mãe, para poder cuidar dos irmãos menores. Assim, os estudos concorriam com uma série de outras 
atribuições designadas para as meninas e vistas como mais urgentes, além dos riscos de se ter meninas "estudadas".

Estudar, seja por três meses ou por três anos, parece, na memória das entrevistadas, conferir à experiência escolar um lugar de insignificância. Dulcina (69 anos) chega a dizer que não tem estudo: "A gente era muito pobrezinho também, né? Plantava roça, né? Mexia na roça. Tanto que nem estudo eu não tenho, né. Eu tive o terceiro ano de grupo, não cheguei a tirar meu diploma; a gente trabalhava muito". O fato de não ter tirado o diploma, ou seja, não ter concluído a quarta série, é um dos motivos que as levam a desconsiderar os três anos de frequência à escola, o que é o caso de 4 das 13 entrevistadas. Entretanto, os três anos equivalem à duração do curso primário das escolas rurais e distritais desde fins do século XIX. Somente as escolas reunidas (agrupamento de pelo menos três escolas distritais) e os grupos escolares é que ofereciam o curso primário com duração de quatro anos. Assim, mesmo tendo frequentado a escola até o limite em que se ofertava nas localidades onde puderam estudar, e considerando que, em 1950, apenas $26 \%$ da população residente no meio rural em Minas Gerais sabia ler e escrever (IBGE,1950), a insignificância atribuída aos três anos pode estar relacionada também aos referenciais atuais, em que estudar três anos é considerado pouco.

A comparação com os dias atuais contribui para se produzir as memórias sobre as escolas do passado como mais precárias, mas também para criticar as escolas e os alunos do presente. A partir desses relatos, podemos apreender vários aspectos dessas escolas rurais (públicas ou particulares), como o espaço físico, a materialidade e, algumas vezes, as práticas escolares e os métodos de ensino utilizados. Era comum as escolas funcionarem em casas, porões de fazendas ou até mesmo no quintal da casa das professoras. Essas formas de organização estiveram presentes ao longo dos séculos XVIII e XIX, antecedendo o processo de estabelecimento de edifícios próprios para o funcionamento das escolas (Vidal \& Faria Filho, 2005). Segundo Margarida (70 anos), "Era assim um povoado mesmo, não era cidade não, era um recanto de roça mesmo que tinha essa escola, sabe? Era numa casa; não era nem assim grupo, nem nada não". Na descrição da escola, que funcionava numa casa, Rosarina (66 anos) afirma: "Ah, era uma casa assim, de professora, uma casa grande, um quintal muito grande... 
Então enchia de cadeirinha ali, banquinho, e aquelas meninada tudo sentada lá estudando... ela passava leitura no caderno...". Para Teresinha (74 anos): "Era uma casa... Um sobrado, uma casa grande, é, era uma escola mesmo, era de sobrado, era grande a escola...".

Alguns fatores intra-escolares também parecem ter contribuído, embora não de modo determinante, para o abandono da escola por parte de algumas entrevistadas. Para essas mulheres, ter sofrido preconceito étnicoracial ou ter sido desvalorizada pelos/as professores/as foram elementos que, somados a outros, fizeram com que não se sentissem estimuladas a dar continuidade aos estudos.

Dulcina (69 anos) se situa entre a crítica e o ressentimento em relação aos programas sociais atuais do governo federal - que fornecem bolsas para as famílias que enviam as crianças à escola - e a outras diferenças do seu tempo de escola: "os grupo tudo tem merenda, né? Tem facilidade; hoje os meninos não tão querendo nada, né! No meu tempo não tinha nada disso, não". Da mesma forma, Beatriz (56 anos) procura fazer os filhos e netos valorizarem o que têm a partir do que ela não teve no passado:

Sabe o quê que eu falo com meus menino? Lá na roça, quando que a gente tava na aula, aqui tem toda mordomia "ah não, eu quero aquela mochila, eu quero aquela ali, eu quero aquela boa ali". Eu falo assim "é, meu filho, lá na roça ninguém tinha mochila, não". Mamãe fazia uma sacolinha de pano, tipo isso aqui, ó. Falava embornal. A gente pendurava aqui, ó, era ali que a gente levava nosso material de ir pra escola.

Por outro lado, muitas se lembram com saudosismo dos rituais de início das atividades, marcado pelo hasteamento da bandeira, do hino nacional e da oração, e também dos recursos e materiais de que dispunham no passado, que já foram abandonados pela escola e são desconhecidos pelas novas gerações, como as canetas de pena, os vidrinhos de tinta, as pedras ou lousas pequenas, a taboada. Poucas delas fazem referência ao uso de livros e cartilhas pelas professoras, mas, quando se lembram, citam até mesmo as lições que estudaram. Graciliana (59 anos) se lembra de ter usado uma cartilha do $\mathrm{ABC}$, que "vinha com a historinha de Joãozinho e Maria". Margarida (70 anos) e Benedita (64 anos) dizem ter utilizado o livro manuscrito16. Benedita cita de cor a lição do "meu sabiá formoso desponta a madrugada, desabrocha a linda rosa esplendorosa...". Rosarina (66 anos) se lembra de ter estudado a Cartilha da Roça17, também bastante utilizada nas 
escolas rurais. Balbina (72 anos), que também se lembra de ter utilizado essa cartilha, recita de cor a principal lição: "minha enxadinha trabalha bem, cortando matinho no vai e vem; minha enxadinha vai descansar, para amanhã recomeçar". Tal cartilha, cuja primeira edição data de 1935, teve mais de uma centena de edições e era direcionada para a alfabetização rápida dos moradores do meio rural; fazia parte, portanto, de uma série de iniciativas públicas de fixação das populações do campo.

Alguns indícios nos permitem verificar a presença de métodos de ensino diversos, destacando-se o método individual, possivelmente por tratarse de escolas multisseriadas. Em alguns casos a professora "passava a leitura no caderno" (Rosarina, 66 anos); para fazer exercícios, utilizavam-se as pedras, nas quais os alunos podiam copiar, apagar e copiar novamente, economizando os cadernos; na ausência de livros didáticos, as lições eram passadas no quadro para serem copiadas. Pode-se notar, também, a influência dos princípios da escola ativa em algumas práticas rememoradas, como, por exemplo, a presença do teatro e o uso de grandes cartazes coloridos.

Nos casos em que os pais contratavam um professor particular para ensinar os filhos, podemos perceber um pouco do funcionamento dessas aulas, que representavam um modo de suprir as necessidades de estudo nas localidades em que não havia a sua oferta. Um desses aspectos, já retratado em outros trabalhos (Silva, 2009; Rodrigues, 1993), é o fato de o professor ser um viajante, que vivia de contratos temporários para ensinar a um grupo de alunos. Ele se fixava por alguns meses em alguma fazenda, ensinava a ler e a escrever, seguindo adiante para outras regiões onde havia a necessidade de seus serviços. O período de contrato era aparentemente variável, como no caso relatado por Divina (75 anos), que se lembra que o professor morou na fazenda por cerca de seis meses a um ano. Os professores contratados são sempre referidos como do sexo masculino, e ensinavam igualmente a meninos e meninas, enquanto nas escolas as professoras eram mulheres.

\section{Considerações finais}

Entrevistar esse grupo de mulheres representou, entre outros aspectos, um exercício de alteridade, o deslocar-se do presente e dos 
referenciais acadêmicos para compreender um tempo e um lugar distantes concreta e simbolicamente - que buscávamos fazer evocar pela memória. Memória que é marcada pela subjetividade - e constituinte dela -, mas indissociável do caráter social e coletivo que the é intrínseco (Halbwachs, 1990). Ao lembrar e contar, nossas entrevistadas recriavam as vivências do passado a partir dos referenciais do presente ${ }^{18}$, muitas vezes dando sentido ou ressignificando o próprio passado a partir dessa experiência de rememorar e narrar. É nesse sentido que, para as entrevistadas, representações em torno da palavra 'infância' estavam relacionadas a duas dimensões: uma delas, de cunho socioeconômico, refere-se aos sujeitos que possuíam condições econômicas melhores do que as delas na época, que tinham acesso a brinquedos industrializados, que eram filhos/as dos donos de terra, que tinham condições de freqüentar níveis mais elevados de ensino, além do curso primário; outra dimensão é a referência aos tempos atuais, a infância dos netos, em um contexto bem diverso do delas. Nesse sentido, o não ter tido infância significa que elas não viveram nem a "infância rica" de meados do século XX e nem a "infância atual", das comodidades da vida urbana, da abundância dos bens de consumo e da escolarização universalizada.

O pertencimento de gênero, associado à pobreza, são os elementos nodais a partir dos quais as narrativas acerca do passado são reconstruídas. Eis porque o trabalho ganha centralidade nessas memórias e, por outro lado, a escola aparece fugidia. O pertencimento étnico-racial é pouco enfatizado nos relatos, embora esteja implicitamente presente em alguns deles, ao relatarem discriminações sofridas na escola por parte de professoras e colegas ou ao dizerem da dificuldade em aceitar os próprios cabelos.

Outro aspecto que deve ser destacado é a concorrência entre os diversos espaços de sociabilidade no processo de constituição das memórias sobre a época "de menina" no meio rural brasileiro, ganhando destaque a família, o trabalho e as comemorações religiosas, em uma época e em um contexto em que a escola ainda não se configurava como uma instituição legitimada e consolidada na formação das novas gerações. Por isso, acreditamos que as pesquisas sobre história da educação e história da infância devem, necessariamente, incluir, no estudo dos processos educativos do passado, instâncias de socialização não escolares, muitas vezes, a depender do lugar e da época, as principais responsáveis pela formação dos sujeitos. 


\section{Notas}

10 presente trabalho resulta de uma pesquisa mais ampla na qual tínhamos o objetivo de compreender, a partir da história oral, os processos de participação na cultura escrita por um grupo de mulheres que possuem atualmente entre 51 e 91 anos. A investigação buscou analisar as instâncias de socialização mais significativas nas comunidades onde essas mulheres nasceram e cresceram, situadas predominantemente na zona rural do estado de Minas Gerais, entre as décadas de 1920 e 1950. A pesquisa, intitulada "Novos letrados": estudos monográficos em Minas Gerais (trajetórias de mulheres e modos de participação nas culturas do escrito), foi coordenada pela professora Ana Maria de Oliveira Galvão da Faculdade de Educação da UFMG e contou com o financiamento do Conselho Nacional de Desenvolvimento Científico e Tecnológico (CNPq).

2 A maioria é originária do sudeste do estado de Minas Gerais: cinco são da Zona da Mata, quatro do Campo das Vertentes, duas do Vale do Rio Doce, uma do Vale do Mucuri, uma do Norte de Minas.

3 Sistema de cultivo da terra no qual o dono fornece o terreno, a casa e, em contrapartida, o meeiro ocupa-se de todo o trabalho e divide os resultados da produção.

4 Arrendar significa alugar a terra de outrem e cultivá-la.

5 Para um aprofundamento dessa discussão, ver, entre outros, o já clássico estudo de Halbwachs (1990) e, no caso brasileiro, de Bosi (1994). Ver, também, Portelli (1996) e Pollack (1989, 1992).

6 Para uma instigante discussão sobre o ato de narrar e a construção de ciclos de vida pelo sujeito-narrador, ver Oliveira, Rego, e Aquino (2006).

7 Optamos por manter, nos excertos de citações das narrativas apresentados no presente artigo, o dialeto falado pelas depoentes.

8 Fogão à lenha.

9 Entretanto, era comum os casos de falecimento ou incapacidade do chefe de família levarem à expulsão da propriedade (Dourado et al., 2000).

10 Brincadeiras coletivas que envolviam tanto meninas quanto meninos. $\mathrm{Na}$ brincadeira 'Passar anel', crianças em fila mantêm suas mãos unidas enquanto uma delas, que possui um anel escondido entre as mãos passa suas mãos entre as das demais crianças, deixando secretamente o anel com uma delas. A criança que adivinhar com quem está o anel será a que vai passar o anel na próxima rodada; as que errarem pagam prenda. Na brincadeira 'Chicote queimado', uma criança esconde um objeto que deverá ser encontrado pelas outras crianças. Quando alguém se aproxima do lugar onde o objeto está escondido, a pessoa que o escondeu diz: "Está quente!" e, caso contrário, diz: "Está frio!", dando pistas. Quando o objeto é encontrado, quem o encontrou grita "Chicote queimado" e ganha o direito de esconder o objeto. As demais brincadeiras são conhecidas como 'Escondidas' e 'Apanhada'.

11 No caso das miniaturas, eram feitas por "mãos especializadas", fugindo da definição de brinquedos populares.

12 Árvore encontrada em regiões de clima tropical. Para maiores detalhes, ver http://www.cnpf.embrapa.br/publica/circtec/edicoes/Circular141.pdf (consultado em 15 de maio de 2011). 
13 Em 1940, as pessoas que se declararam católicas compunham 97,57\% da população de Minas Gerais (IBGE, 1950).

$14 \mathrm{Na}$ análise realizada por Zaluar, em meados do século $\mathrm{XX}$, as práticas religiosas populares passavam por mudanças, havendo um progressivo controle por parte das autoridades católicas oficiais. Um dos reflexos dessas mudanças se refere à figura do 'festeiro', que tradicionalmente era representado por alguém da elite da sociedade. Este assumia o lugar de autoridade e oferecia a residência para a realização das atividades, além de distribuir alimentos aos participantes. Com as mudanças, o padre passava a sortear os nomes dos responsáveis por organizar as festas, e a comunidade participava realizando doações, organizando leilões e as barraquinhas, onde os alimentos passaram a ser vendidos e não mais distribuídos. Desse modo, o maior controle da igreja representou a "democratização" na realização e nas formas de participação nas festas católicas em comunidades rurais nas décadas de 1940 e 1950 (dos estados de São Paulo, Bahia, Amazonas e Alagoas).

15 De acordo com a legislação estadual e federal, as escolas rurais seriam aquelas estabelecidas em localidades cuja população fosse inferior a 1000 habitantes ou 150 crianças de ambos os sexos, de 7 a 13 anos completos na área abrangida pelo perímetro escolar. Essas escolas deveriam ministrar um programa semelhante ao das escolas urbanas, porém simplificado; deveria dar-se ênfase ao ensino da leitura, escrita e à realização das quatro operações matemáticas. Nas escolas rurais, distritais e urbanas singulares, a duração do ensino primário seria de três anos, enquanto nas escolas reunidas, distritais e urbanas e nos grupos escolares, a duração seria de quatro anos. Ver maiores detalhes em Pinho, 2009, p. 40.

16 Os livros manuscritos, também chamados de paleógrafos, foram impressos no período de 1840 a 1960 no Brasil, por meio da litografia, e os caracteres eram "bordados", semelhante à letra cursiva. Para maiores detalhes ver Batista \& Galvão, 2009. Segundo os autores, era corrente o uso dos livros manuscritos como material de leitura nas escolas brasileiras ao longo dos séculos XIX e XX.

17 Seu nome original é Cartilha na roça, de autoria de Renato Sêneca Fleury. Ver detalhes em http://www.crmariocovas.sp.gov.br/obj_a.php?t=cartilhas02 (consultado em 01 de junho de 2011).

18 Nessa direção, os depoimentos orais são, muitas vezes, marcados por uma tentativa de organizar as experiências do passado em uma narrativa coesa e coerente com o lugar ocupado pela entrevistada no presente. Para um aprofundamento sobre essa temática, ver, entre outros, Bourdieu (1996).

\section{Referências}

Amado, J. (2007). Universo dos brinquedos populares (2a ed.). Coimbra: Quarteto Editora.

Ariès, P. (1981). História social da criança e da família. Rio de Janeiro: Zahar.

Batista, A. A. G., \& Galvão, A. M. O. (2009). Livros escolares de leitura no Brasil: Elementos para uma história. Campinas, SP: Mercado de Letras. 
Bosi, E. (1994). Memória e sociedade. Lembranças de velhos ( $3^{a}$ ed.). São Paulo: Companhia das Letras.

Bourdieu, P. (1996). A ilusão biográfica. In M. M. Ferreira \& J. Amado (Orgs.), Usos e abusos da história oral (pp. 183-191). Rio de Janeiro: Fundação Getúlio Vargas.

Chartier, R. (1990). A história cultural entre práticas e representações. Lisboa: Bertrand; Brasil: Difel.

Coelho, C. M. T. (2009). Viver no campo e a educação: Experiências escolares de jovens em uma escola família agrícola (Dissertação de mestrado). Faculdade de Educação - Universidade Federal de Minas Gerais, Belo Horizonte, Brasil.

Dourado, A., Dabat, C., \& Araújo, T. C. (2000). Crianças e adolescentes nos canaviais de Pernambuco. In M. D. Priore (Org.), História das crianças no Brasil (pp. 407436). São Paulo: Cortez.

Gannan, S. T. (1995). Travail agricole et école primaire en milieu rural brésilien (Ph. D. Thèses). Faculté des Études Supérieures de I'Université Laval / Faculté des Sciences de l'Éducation Juin, Québec, Canada.

Gélis, J. (1993). A individualização da criança. In P. Ariès \& R. Chartier (Orgs.), História da vida privada: Da renascença ao século das luzes (vol. 3) (pp. 311-329). São Paulo: Companhia das Letras.

Gouvêa, M. C. S. de (2002). Infância, sociedade e cultura. In A. Carvalho, F. Salles \& M. Guimarães (Orgs.), Desenvolvimento e aprendizagem (pp. 13-29). Belo Horizonte: Editora da Universidade Federal de Minas Gerais.

Halbwachs, M. (1990). A memória coletiva. São Paulo: Vértice.

Instituto Brasileiro de Geografia e Estatística (IBGE) (1950). Enciclopédia dos municípios brasileiros (vols. XXIV e XXV). Rio de Janeiro. Disponível em http://biblioteca.ibge.gov.br/ (acesso em 10 de outubro de 2010).

Kuhlmann Jr., M. (1998). Infância e educação infantil: Uma abordagem histórica. Porto Alegre: Mediação.

Kuhlmann Jr., M., \& Fernandes, R. (2004). Sobre a história da infância. In L. M. de Faria Filho (Org.), A infância e sua educação. Materiais, práticas e representações (Portugal e Brasil) (pp. 15-33). Belo Horizonte: Autêntica.

Malheiros, C. S. (2009). Escola, saberes e cotidiano no meio rural: Um estudo sobre os(as) jovens do Sertão da Bahia (Dissertação de mestrado). Faculdade de Educação - Universidade de Brasília, Brasil.

Mello, J. M. C., \& Novais, F. A. (1998). Capitalismo tardio e sociabilidade moderna. In L. M. Schwarcz (Org.), História da vida privada no Brasil. Vol. 4. Contrastes da intimidade contemporânea (pp. 559-658). São Paulo: Companhia das Letras.

Montes, M. L. (1998). As figuras do sagrado: Entre o público e o privado. In L. M. Schwarcz (Org.), História da vida privada no Brasil. Vol. 4. Contrastes da intimidade contemporânea (pp. 63-171). São Paulo: Companhia das Letras.

Musial, G. B. S. (2011). A emergência da escola rural em Minas Gerais (1892-1899): Quando a distinção possibilita a exclusão (Tese de doutorado). Faculdade de Educação - Universidade Federal de Minas Gerais, Belo Horizonte, Brasil. 
Oliveira, M. K., Rego, T. C., \& Aquino, J. G. (2006). Desenvolvimento psicológico e constituição de subjetividades: Ciclo de vida, narrativas autobiográficas e tensões da contemporaneidade. Pró-Posições, vol. 17, n. 2 (50), 119-38.

Pollack, M. (1989). Memória, esquecimento, silêncio. Estudos Históricos, 2(3), 3-15.

Pollack, M. (1992). Memória e identidade social. Estudos Históricos, 5(10), 200-212.

Portelli, A. (1996). O massacre de Civitella Val di Chiana (Toscana: 29 de junho de 1944): Mito, política, luto e senso comum. In M. M. Ferreira \& J. Amado (Orgs.), Usos e abusos da história oral (pp. 103-130). Rio de Janeiro: Fundação Getúlio Vargas.

Pinho, L. A. (2009). Educação e saúde nos cursos de aperfeiçoamento para professores rurais - Fazenda do Rosário (Minas Gerais, 1947-1956) (Dissertação de mestrado). Faculdade de Educação - Universidade Federal de Minas Gerais, Belo Horiozonte, Brasil.

Rizzini, I. (2000). Pequenos trabalhadores do Brasil. In M. D. Priore (Org.), História das crianças no Brasil (pp. 376-406). São Paulo: Contexto.

Rodrigues, D. A. (1993). O significado da escola rural revelado na trilha do trabalho (Dissertação de mestrado). Faculdade de Educação - Universidade Federal de Minas Gerais, Belo Horizonte, Brasil.

Sarmento, M. J. (1997). As crianças e a infância: Definindo conceitos, delimitando o campo. In M. Pinto \& M. J. Sarmento (Coords.), As crianças. Contextos e identidades. Braga: Universidade do Minho - Centro de Estudos da Criança.

Souza, J. V. A. (2009). A festa e o calendário religioso na demarcação dos tempos da vida social. In Globalização do regional e regionalização do global: Anais do I Congresso em Desenvolvimento Social (v. 1) (pp. 1-14).

Vidal, D., \& Faria Filho, L. M. (Orgs.). (2005). As lentes da história. Estudos de história e historiografia da educação no Brasil. Campinas, SP: Autores Associados.

Zaluar, A. (1983). Os homens de Deus. Um estudo dos santos e das festas no catolicismo popular. Rio de Janeiro: Zahar Editores. 


\section{MEMORIES OF CHILDHOOD IN A RURAL AREA: THE SCHOOL AND OTHER SPACES OF SOCIABILITY (MINAS GERAIS - BRAZIL, 1920-1950)}

\section{Abstract}

This paper analyses the representations of childhood by women of rural communities from the state of Minas Gerais, in the first half of the $20^{\text {th }}$ century, who have migrated to Belo Horizonte as adults and live in a suburban area of the Minas Gerais capital. We interviewed 13 women, and gathered demographic data and educational legislation of that period. During the interviews, the recurrent statement "I had no childhood" can be understood as a contraposition made by them between a supposed ideal childhood, related to socially privileged classes, and childhood nowadays, the one they were excluded from. The evoked memories refer to the intense work routine in the field and in other people's houses, the hardships to frequent a school, the poor state of the clothes, the lack of toys, but also the joyful moments of games and the participation on religious celebrations. Family, work and religion compete with the school as important spaces of sociability.

Keywords

Childhood; Rural school; Women; Sociability spaces

\section{MEMOIRES SUR L'ENFANCE DANS LA CAMPAGNE: L'ÉCOLE ET D'AUTRES ESPACES DE SOCIABILITÉ (MINAS GERAIS - BRÉSIL, 1920-1950)}

\section{Résumé}

Ce travail a pour but d'analyser les représentations sur l'enfance de femmes originaires de la campagne de Minas Gerais, dans la première moitié du siècle $X X$, qui ont migré pour Belo Horizonte dans la vie d'adulte et qui habitent dans des quartiers périphériques de cette ville. On a utilisé des entretiens avec 13 femmes, des données démographiques et de la législation éducationnelle de la période citée. Dans les entretiens, l'affirmation "moi, je n'eus pas enfance" 
peut être regardée comme une opposition à une idée d'enfance idéale, par comparaison aux mieux socialement privilégiés, et l'enfance de l'actualité, auxquels elles ne font partie. Les mémoires relatées montrent l'intensité des journées de travail dans la campagne et le travail chez les autres, la difficulté d'aller à l'école, la précarité des vêtements, l'inexistence de jouets, mais aussi des moments de joie autour des jeux et de la participation dans les célébrations religieuses. Famille, travail et religion sont concurrents avec l'école comme des espaces très importants de sociabilité.

Mots-clé

Enfance; École rurale; Femmes; Espace de sociabilité

Recebido em Julho/2011

Aceite para publicação em Julho/2012

Toda a correspondência relativa a este artigo deve ser enviada para: Mônica Yumi Jinzenji, Rua dos Aeroviários, 420. Bairro Liberdade/Pampulha, Belo Horizonte, CEP: 31 270-330 Minas Gerais, Brasil. E-mail: monicayj@ufmg.br 